\title{
PLANEJAMENTO DE CRECHE: UM DESAFIO PARA AS EMPRESAS
}

\author{
Taka Oguisso *
}

\section{1 - INTRODUÇÃO}

Observa-se uma crescente preocupação das grandes empresas, públicas ou privadas, no sentido de oferecer aos seus funcionários, incentivos outros, que não os apenas de ordem salarial, com o fim de alcançar melhor produtividade, rendimento e bem-estar dessas comunidades. Tais incentivos se expressam por meio de restaurante próprio, assistência médica, condução e, também, serviços de creche. A prestação destes serviços ao pessoal constitui compensação, muitas vezes, até melhor que altos salários, pela tranqüilidade e segurança que conferem ao usuário.

A creche é, ainda, uma instituição sem muitos adeptos entre algumas grandes empresas, mas está surgindo no panorama das cidades grandes, como uma necessidade vital; ela constitui inequivocamente, uma solução setorial para os problemas atuais da sociedade contemporânea, onde cada vez mais se exige a participação da mulher como força de trabalho.

0 presente estudo visa, despretensiosamente, oferecer alguns subsídios para a construção ou instalação de creche para filhos de funcionários de uma empresa.

Faz-se oportuno lembrar que a Decläração dos Direitos da Criança, proclamada em novembro de 1959 na Assembléia Geral das Nações Unidas, dispõe em seu Princípio 2. que "a criança gozará proteção especial e ser-lhe-ão proporcionadas oportunidades e facilidades, por lei e por outros meios, a fim de lhe facultar o desenvolvimento físico, mental, moral, espiritual e social, de forma sadia e normal e em condições de liberdade e dignidade. Na insti-

(*) Enfermeira da Coordenação de Planejamento da Superintendencia Regional em São Paulo, do Instituto Nacional de Previdéncia Social (INPS). 
tuição de leis visando este objetivo levar-se-ão em conta, sobretudo, os melhores interesses da criança".

Também a Consolidação das Leis do Trabalho, no seu artigo $389, \S 1 .^{\circ}$, reza que "os estabelecimentos em que trabalham pelo menos trinta mulheres com mais de dezesseis anos de idade, terão local apropriado, onde seja permitido às empregadas guardar sob vigilância e assistência, os seus filhos no período de amamentação".

Além dos aspectos legais pesquisados, este trabalho é o resultado de observações realizadas em visitas a diversas creches, da participação em equipes de trabalho com arquitetos, engenheiros e médicos, além da experiência vivida e sentida no decorrer do exercício profissional.

\section{2 - ASPECTOS DO PLANEJAMENTO}

Trata-se de um imperativo de sobrevivência para qualquer entidade procurar o meio mais eficiente, simples, seguro e econômico para alcançar seus objetivos. E por isto que, primeiramente, devem ser fixados os objetivos, isto é, o que se pretende fazer, a quem e como atender. E hoje, pacificamente, aceito que o planejamento cientificamente elaborado por uma equipe técnica e multiprofissional é fundamental para o êxito do empreendimento, qualquer que seja a sua natureza.

As observações a seguir desenvolvidas, poderão servir de roteiro para pesquisas posteriores, pois o campo apresenta-se ainda incipiente e propício para os estudiosos.

\section{1 - Capacidade}

O planejamento inicial comporta um levantamento das necessidades entre todos os funcionários, através do preenchimento de questionário para este fim elaborado. A tabulação dos dados obtidos evidenciará a faixa das necessidades existentes e poderá auxiliar no estabelecimento das diretrizes que poderão melhor equacionar os problemas.

Obviamente, para uma pequena empresa torna-se mais fácil e mais econômico firmar convênios com creches distritais existentes do que instalar uma em seus domínios.

Porém, empresas de grande porte já estão se conscientizando de que maior rendimento é obtido através de melhores condições de trabalho e estabilidade de pessoal. Portanto, tratando-se de uma instituição com quadro de pessoal formado por elementos de ambos os sexos, e que se tenha apurado ser o grupo etário predominante constituído por indivíduos de 20 a 40 anos de idade, procura-se de- 
terminar a capacidade que deverá ter a creche ou centro infantil. A tendência moderna é a substituição de creches por centros infantis, cuja conceituação é mais ampla, pois abrange desde o lactente até o pré-escolar inclusive, ao passo que a creche, dentro deste conceito, visa a assistência até os 24 meses de idade.

As visitas efetuadas em algumas creches possibilitaram a constatação de condições e fatores dificultantes ao trabalho, bem como alternativas e possíveis soluções que poderão favorecer o melhor desempenho das atividades com maior aproveitamento para as crianças.

Um dado inicial buscado nas visitas foi a verificação de uma possível relação entre o total de funcionários e a capacidade necessária da creche. Face a dificuldade na obtenção de dados quanto ao número de funcionários da empresa por sexo, tomou-se por base uma estimativa fornecida pelos respectivos órgãos:

QUADRO DEMONSTRATIVO DA PROPORÇÃO ENTRE O N. ${ }^{\circ}$ TOTAL DE FUNCIONARIOS E A CAPACIDADE DA CRECHE

\begin{tabular}{|c|c|c|c|}
\hline Creche & $\begin{array}{l}\text { Número } \\
\text { estimado de } \\
\text { funcionários }\end{array}$ & $\begin{array}{c}\text { Capacidade } \\
\text { da } \\
\text { Creche }\end{array}$ & $\begin{array}{c}\text { Média } \\
\text { Percentual }\end{array}$ \\
\hline $\mathrm{A} . . .$. & 6.000 & 100 & $1,6 \%$ \\
\hline B..... & 3.500 & 52 & $1,4 \%$ \\
\hline $\mathrm{C} \ldots \ldots$ & 6.000 & 110 & $1,8 \%$ \\
\hline D..... & 1.200 & 60 & $5,0 \%$ \\
\hline SOMA . . . . & 16.700 & 322 & $1,9 \%$ \\
\hline
\end{tabular}

Pelo quadro acima levantou-se uma média percentual da relação $n .^{9}$ de funcionários - capacidade da creche, que analisada pode fornecer elementos para a determinação da capacidade ideal. E interessante observar que todas as creches visitadas, mesmo as excluídas do quadro acima por não pertencerem a uma empresa, estavam com suas capacidades esgotadas. Com exceção da creche D, cuja capacidade está três vezes acima da média geral, e onde só havia cinco mães inscritas, aguardando vaga para seus filhos, nas demais creches a demanda chegava a atingir 60 crianças à espera de vaga, como é o caso da creche $C$. A instituição inantenedora da creche A já está com projeto pronto para a construção de nova creche para mais de 100 (cem) crianças. 
A simples análise destes dados evidencia a necessidade de elevar-se a média percentual para dar cobertura à demanda existente. Naturalmente a qualidade da assistência prestada à criança influi diretamente na demanda, como é o caso da creche $D$.

Ante estes fatos, dobrando-se a média encontrada e estabelecendo-se uma capacidade mínima de $4 \%$ do número total de funcionários poderia ser razoável para o atendimento da demanda. As pequenas variações dependerão da predominância maior ou menor de elementos do sexo feminino, sua faixa etária, nível sócio-econômico, escolaridade etc. que certamente poderão determinar oscilações para mais. Entretanto, desaconselha-se creche com capacidade superior a 100 crianças ante o risco de prejudicar a qualidade da assistência a ser prestada, especialmente quanto à individualização nos cuidados.

\section{2 - Localização e Construção}

Naturalmente, o ideal seria que desde a fase de anteprojeto de construção do prédio da empresa, a creche já estivesse incluída no seu planejamento, como foi observado na creche D. A escolha do local da instituição deve ser feita de maneira criteriosa, atendendo-se a fatores como distância dos focos de poluição do ar, área livre que receba sol, em especial o da manhã, instalações hidráulicas e elétricas, facilidade de acesso, proteção contra incêndios e acidentes.

A satisfação destes requisitos em prédios de construção vertical é possível, localizando-se a creche no último pavimento (creche $\mathrm{C}$ ), ou se intermediário (creche D), colocando-a em tal posição que o solário não possa ser alvo de objetos como cigarros, papéis, água, lixo etc. que possam ser atirados pelas janelas dos pavimentos superiores. Se a empresa ocupar instalações no sentido horizontal em um ou dois pavimentos, e tiver ainda terreno livre, o ideal é a localização da creche em área isolada (creche A) atendendo-se a todas aquelas condições mencionadas. Esta crcche oferece a vantagem de que a criança poderá entrar em contato direto com a natureza.

Quanto aos aspectos construtivos gerais, é importante que as áreas de circulação das crianças sejam de material de fácil limpeza e conservação, com arejamento suficiente, iluminação natural e artificial adequada, prevendo-se um total de 15 a $20 \mathrm{~m}^{2}$ de área total por criança. Algumas áreas podem ser opcionais, como por exemplo, a empresa que possua restaurante com cozinha própria. Neste caso, o preparo da alímentação das crianças poderá ser na mesma. Igualmente, se-possuir lavanderia ou lactário, não haverá necessidade de previsão destas dependências na creche. 
As áreás necessárias à creche podem ser distribuídas em três conjuntos distintos:

2.2.1 - área de administração

2.2.2 - área de materno-infantil

2.2.3 - área de serviços auxiliares

\section{Area de Administração}

Esta área compõem-se de sala de espera, recepção, secretaria, chefia e sala de reuniões. Destina-se ao planejamento, coordenação, organização e controle das atividades da creche. Deve ocupar uma árca correspondente a 60 ou $70 \mathrm{~m}^{2}$ e cferecer as comodidades de sanitários próximos. A sala de reuniões, que servirá para orientação de grupos de mães e para treinamento de funcionários, deve permitir a acomodação confortável de vinte pessoas. A necessidade desta sala foi sentida em todas as creches, pois nenhuma delas a possuia.

\section{Area Materno-Infantil}

E constituída pelas salas de amamentação, berçário, repouso, recreação, solário, refeitório, salas de aula, consultório médico, sala de enfermagem e isolamento.

Todas as áreas em que as crianças permanecerão maior tempo, devem ter a localização cuidadosamente estudada a fim de que recebam sol e estejam protegidas contra o vento. O piso deve ser de material de fácil limpeza, com cantos arredondados, paredes com tintas laváveis em cores alegres e harmoniosas e decoração com motivos infantis. Os sanitários e lavatórios nos tamanhos e alturas adequadas, devem estar distribuídos na proporção de um eonjunto para cada 6 a 8 crianças. Nos sanitários deve haver previsão de área com pia especial para lavagem dos urinóis individuais e local para sua guarda. Todos os fios devem estar embutidos e as tomadas e interruptores devem estar a $1,50 \mathrm{~m}$ do chão, a fim de prevenir acidentes.

A sala de amamentação deve prever uma área de 9 a $10 \mathrm{~m}^{2}$ com instalação de lavatório, porta-toalhas, uma mesinha e um pequeno armário para guarda de aventais e apetrechos necessários para a amamentação.

O berçário deve ser subdividido em duas áreas distintas, com capacidade máxima para 15 crianças cada uma. Estas áreas são destinadas, uma para lactentes, isto é, bebês de zero a 8 ou 9 meses e outra para bebês de 9 a 18 ou 24 meses. A separação destas 
idades deve ser flexível, atendendo-se mais ao desenvolvimento psico-motor e social da criança do que à idade cronológica. 0 berçário deve prever uma área de $3 \mathrm{~m}^{2}$ por criança e cubagem (volume de oxigênio existente no ar atmosférico por metro cúbico) de $6 \mathrm{~m}^{3}$ no mínimo. A área deve, se possível, estar dotada de um ou dois aparelhos de ar condicionado e situar-se próxima ao lactário e sala de amamentação. As paredes contíguas aos corredores de circulação devem ter amplos visores para facilitar a observação das crianças e a supervisão das funcionárias. As janelas ou vitrôs devem ter proteção com telas milimetradas, se não existir aparelho de ar condicionado, e um sistema para escurecimento do ambiente, a fim de favorecer o repouso. A porta deve ter dispositivo que permita sua abertura e fechamento de maneira suave e silenciosa. Dentro do berçário deve-se prever a instalação de água quente e fria com chuveirinhos sobre banheiras infantis, com tampo ou mesa acolchoada para troca de roupa da criança. Deve haver pelo menos uma banheirinha para cada área do berçário. Sob as mesas devem ser previstas prateleiras para a guarda da roupa de cama e banho. Deve haver também outra mesa-armário com prateleiras e divisões ou escaninhos para a guarda das sacolas com a roupa pessoal do bebê. Além dos berços e cercados deve haver na sala algumas cadeirinhas próprias para alimentação dos bebês maiores, andadores e cadeiras para as funcionárias. Brinquedos adequados à idade e que pela sua cor, textura e tamanho estimulem o desenvolvimento psicomotor da criança são elementos integrantes indispensáveis ao berçário.

A sala de repouso destina-se ao repouso das crianças maiores de 18 a 24 meses, após o almoço. Pode-se utilizar camas de armar, baixas, de lona e ferro tubular, sem arestas, com colchãozinho de sspuma de latex individual. Uma área de $2 \mathrm{~m}^{2}$ por criança é o bastante, desde que haja arejamento suficiente e facilidade para escurecimento. Esta sala pode servir também, em dias de chuva, para complementar a área de recreação interna, e servir para projeções de filmes educativos ou recreativos.

A sala de recreação pode ser comum ao refeitório. Neste caso, além das mesinhas e cadeirinhas deve haver armários para a guarda dos brinquedos. Deve localizar-se próximo à copa-cozinha e aos sanitários. Nestes sanitários deverão ser previstos, também, box com chuveiros, na proporção de um para cada 10 crianças maiores. Considerando-se a dupla utilização desta área, deve-se prever um mínimo de $3 \mathrm{~m}^{2}$ por criança, farta iluminação natural, arejamento suficiente, vidro temperado nas janelas, grades de proteção, telas milimetradas e dispositivos de segurança contra incêndios, explosões e outros acidentes.

O solário é a área livre e descoberta para a recreação externa das crianças. 
Se a localização da creche é térrea, deve-se prever a plantação de algumas árvores e flores. 0 gramado, em geral, não resiste por muito tempo ao volume previsto de circulação, e exige tratamento cuidadoso a fim de impedir o desenvolvimento de insetos e animais nocivos. O importante é que o solo, de terra batida ou gramado, seja mantido sempre limpo.

O solário em pavimentos elevados deve ter piso de cerâmica ou ladrilhos. Em qualquer das hipóteses de localização da creche, não deve faltar no solário um tanque de areia, se possível com tampa, a fim de facilitar a conservação e limpeza. A mureta do tanque de areia deve prever arredondamento de todos os cantos, e ser de altura que impeça o vôo da areia pelo solário e outros edifícios ou áreas. 0 tanque de areia, quando em solário de edifício, deve ter inferiormente um sistema para escoamento de água de chuva, a fim de impedir infiltração nas paredes.

Além do tanque de areia deve haver gangorras, balanços, escorregadoras e piscinas, desmontáveis, de lona ou plástico.

O solário deverá ser o mais amplo possível, embora nem sempre possa ser destinado uma área ideal, que seria de 5 a $8 \mathrm{~m}^{2}$ por criança. Sendo área espaçosa, deve haver bebedouros (um para cada 10 ou 15 crianças), conjunto de sanitários e lavatórios para as crianças e estar protegida por altos muros, que garantam a tranqüilidade de seus responsáveis.

As salas de aula serão necessárias se a assistência for estendida a crianças de 2 a 6 anos. Destinam-se tais áreas para desen. volvimento de programas de maternal, jardim da infância e pré-primário. A separação das crianças far-se-á por idade e desenvolvimento psicomotor e reunidas em grupos de 10 a 15. Os requisitos relativos a posição das salas, iluminação, arejamento, pisos e paredes laváveis, mobiliário adequado, decoração etc. devem ser estruturados dentro das exigências arquitetônicas e construtivas normais.

O consultório médico é o local onde o pediatra fará os exames clínicos necessários para a admissão e controle de saúde das crianças. Deve ter de 10 a $12 \mathrm{~m}^{2}$, sanitário anexo, lavatório, portatoalha e facilidades para a disposição cômoda e funcional de uma mesa para exame clínico, escrivaninha, cadeiras, balança pesa-bebê e pesa-gente, antropômetro, armário para guarda de material. Para o controle de saúde dos bebês é preferível que o pediatra se locomova até o berçário, como é o caso da creche $D$, podendo assim examinar a criança em seu ambiente, e ao mesmo tempo familiarizar-se melhor com as crianças e observá-las em seu comportamento, bem como observar e orientar a assistência que vem sendo prestada pelas funcionárias. 
A sala de enfermagem é a área onde a auxiliar de enfermagem deverá preparar os medicamentos e tratamentos a serem administrados, bem como fazer os pequenos curativos. Deve ter pia com tampo de mármore ou similar, armário para medicamentos e outros materiais necessários.

O isolamento deve ser localizado junto ao consultório e à sala de enfermagem. Deve ter piso de material de fácil limpeza, cantos arredondados, lavatório e sanitários privativos, janelas dotadas de telas. É a área onde a criança que apresentar sintomatologia de processo infeccioso deve permanecer, enquanto aguarda a vinda da mãe. Portanto deve ter dois ou três berços de tamanhos diversos separados por box em área mínima de $12 \mathrm{~m}^{2}$.

\section{Area de Serviços Auxiliares}

E constituída de copa, cozinha, lactário, despensa, lavanderia, rouparia, vestiário e copa para funcionárias e a área para guarda do material de limpeza.

E a área que se destina à manutenção dos serviços de apoio à creche. Conforme referência inicial, a cozinha, lactário e lavanderia são opcionais, pois se a instituição conta com estas instalações, elas poderão ser utilizadas também para atendimento às crianças. Mas a ausência de cozinha e lactário na creche não dispensa a copa, que servirá para distribuição dos alimentos, e também para o preparo de sucos, sopas e lanches para a tarde.

Mesmo que a empresa tenha cozinha, o ideal seria que a creche tivesse sua cozinha própria, $\mathrm{f}$ ois assim o cardápio poderia ser executado mais de acordo com as necessidades infantis. A cozinha deve obedecer também aos requisitos exigíveis de construção, tais como azulejos, telas nas janelas, iluminação e ventilação adequadas, piso lavável, exaustor, pia com tampo de mármore ou similar, despensa para guarda de mantimentos etc.

O lactário, com um mínimo de $12 \mathrm{~m}^{2}$, deve ficar próximo ao berçário e ser dotado de pia com tampo de mármore ou similar, azulejos nas paredes, janelas com telas e tanques azulejados para esterilização das mamadeiras. Deve prever área para fogão, geladeira e armário para guarda de louças e utensílios.

A lavanderia e a rouparia, com uma área de $20 \mathrm{~m}^{2}$, destinam-se a lavar, passar, reparar e guardar toalhas de mesa e banho e lençóis utilizados pelas crianças. Basta uma máquina de lavar e secar doméstica e mesas para passar a ferro a roupa lavada.

Para a guarda do material de limpeza é necessário mais que um armário embutido grande ou área junto à lavanderia ou outro local disponível. 
O vestiário de funcionárias deve ser previsto numa área com sanitários, chuveiros, lavatórios, espelhos, além de espaço para acomodação de armários roupeiros individuais. Aconselha-se também uma pequena copa privativa para funcionárias, para o conforto e o descanso merecido nos intervalos do trabalho.

\section{3. - Pessoal}

A infância constitui "uma fase da vida que, se prejudicada, deixará marcas profundas". Neste período, a personalidade está em formação e precisa de estabilidade e segurança. Portanto o pessoal que irá lidar com crianças deve possuir qualidades especiais, sejam técnicas ou morais.

E do pessoal que dependerá o padrão de assistência à criança. Portanto é imprescindível que a seleção seja criteriosamente feita, buscancio-se algumas qualidades indispensáveis, tais como saúde perfeita, gosto e facilidade no trato com crianças, senso de responsabilidade, paciência, calma, alegria e entusiasmo pelo trabalho. Estas qualidades poderão ser aferidas não só na entrevista inicial a ser feita pela chefia, como durante o treinamento e estágio probatório, pela supervisão constante e avaliação periódica. Não se poderia pretender que cada creche ou centro infantil tivesse a seu serviço uma equipe de profissionais de gabarito com psicóloga, enfermeira, pedagoga, nutricionistas, assistente social, administradora de empresa etc. . Uma destas profissionais que reúna os conhecimentos e habilidade a respeito de higiene, puericultura, nutrição, psicologia infantil, pedagogia, sociologia e administração poderá assumir a chefia. Entretanto, não deve faltar à creche, pelo menos, um médico e uma professora primária.

Qualquer que seja a profissional, de uma das carreiras acima mencionadas, que assuma a direção, deve ser do sexo feminino, pois a mulher está melhor talhada e possui qualidades inerentes que lhe facilitarão o trabalho de aproximação e cuidados à criança. Portanto, a creche ou centro infantil deverá ter em seu quadro de pessoal, os seguintes profissionais: médico, professora (uma para cada 10 a 15 crianças maiores de 2 anos), 2 ou 3 cozinheiras, 2 copeiras, pájens ou atendentes (uma para cada 6 a 8 crianças), 3 ou 4 serviçais, além de uma escriturária e uma auxiliar de enfermagem.

\section{4 - Organização}

A organização e o funcionamento da creche dependerão muito das finalidades, do tipo de trabalho, do interesse e dos meios proporcionados pela entidade mantenedora. Entretanto, alguns aspec- 
tos não podem ser esquecidos, como parâmetros para organização e atuação.

A creche deve ter objetivos fixados previamente, com regulamento próprio, rotinas escritas de trabalho, atribuições do pessoal, programas de atividades com mães e crianças etc..

Além de possibilitar tranqüilidade à mãe que trabalha na instituição, a creche deve ainda promover palestras e cursos em diversos horários para o seu pessoal e para as mães ou pais, procurando-se' o melhor entrosamento, a fim de que no lar não haja solução de continuidade na orientação recebida, pela criança. A creche deve, ainda, ter como objetivo o controle da saúde da criança, mas fazendo-se com que a mãe participe deste trabalho, seja levando a criança para as vacinações, seja para o controle odontológico ou realização de exames complementares de diagnósticos nos serviços oficiais ou particulares indicados pelo médico.

As rotinas de trabalho devem prever a distribuição das atividades da criança não só durante o dia, mas para cada dia da semana e até do mês.

A creche ou centro infantil pertencente a uma empresa de trabalho ininterrupto pode ter seu funcionamento permitido inclusive aos sábados, domingos e feriados (caso da creche A), mas em nenhuma hipótese deve funcionar à noite e nem encerrar suas atividades tarde da noite, pois se já não é recomendável retirar crianças da cama às cinco ou seis da manhã para levá-las à creche, muito menos à noite, depois das 20 ou 21 horas.

Para facilitar a comunicação, as creches A e C mantêm um livro na portaria ou recepção, para a mãe registrar algum fato, pedido ou sintoma relativo à criança, para que a observação possa ser continuada durante o dia na creche. Da mesma forma, no fim do dia, a mãe deve receber, por escrito ou verbalmente, as informações sobre ocorrências especiais quanto a problemas da criança relativos à alimentação, saúde, desenvolvimento e outros, sobretudo se se tratar de lactentes.

A creche $\mathrm{C}$ mantém um cadastro de cada criança com fotografia d $\alpha$ mãe ou responsável, e também, de outra pessoa autorizada pela mãe a retirar a criança da creche, o que realmente constitui importante fator de segurança.

Os aspectos enfocados no planejamento de uma creche com toda a sua problemática peculiar, visam demonstrar que a creche deve ser sempre de alto padrão; não pode, nunca, ser um "depósito de crianças". 


\section{3 - CONCLUSÕES}

Se considerarmos os programas de assistência à infância como reflexos que são da importância que uma sociedade atribui à criança, pode-se dizer que o nosso meio está começando a despertar para o problema. Todos os gastos destinados a assegurar uma infância sadia são investimentos solidamente rentáveis para o desenvolvimento da nação.

Assim sendo, qualquer planejamento de creche não pode se orientar apenas por cifras exíguas e rigidamente vinculadas a comportamentos de despesas. Não são despesas improdutivas, mas altos investimentos com farta compensação. E necessário que os governos, empresários e industriais se compenetrem cada vez mais desta responsabilidade e perspectiva.

Cabe também a nós, enfermeiras, despertar para este campo de trabalho, onde são tão grandes as oportunidades de desempenhar atividades profissionais e desenvolver habilidades e técnicas, cspecialmente na área educativa e na saúde pública.

Há, portanto, um relevante papel à espera de que a enfermeira possa dar sua melhor contribuição. Trata-se de nova dimensão de trabalho, com amplas possibilidades de realização pessoal e profissional.

Para a empresa moderna, a instalação de creche constitui, realmente, um desafio. Para forjar o desenvolvimento, é necessário haver a compreensão do alcance e profundidade do problema, a visão projetada para o futuro, o sacrifício pessoal no presente para aceitar aquele desafio, e lançar-se à luta, avançando com o progresso e evolução tecnológica.

Se cada vez se torna mais difícil à criança ser cuidada e educada no próprio lar, pela própria mãe, não seja ela sacrificada a pagar tão alto tributo ao progresso, vendo-lhe negadas as condições mínimas ao seu desenvolvimento hígido, em seus aspectos físicos, psíquicos e lúdicos.

Resta-nos, pois a responsabilidade da aplicação dos melhores esforços e recursos no sentido de propiciar o desenvolvimento integral da criança, através de creches e centros infantis.

Finalmente, cumpre lembrar o Princípio $6 .^{\circ}$ da Declaração dos Direitos da Criança, que dispõe: "Para o desenvolvimento completo e harmonioso de sua personalidade, a criança precisa de amor e compreensão. Criar-se-á, sempre que possível, aos cuidados e sob a responsabilidade dos pais e, em qualquer hipótese, um ambiente de afeto e de segurança moral e material; salvo circunstâncias excep. cionais, a criança de tenra idade não será apartada da mãe..." 


\section{REFERENCIAS BIBLIOGRÁFICAS}

1 - CONSOLIDAÇÃO DAS LEIS DO TRABALHO. Decreto-lei 5.452, de $10^{\circ}$ de maio de 1943.

2 - ONU. A Declaração dos Direitos da Criança, novembro de 1959.

3 - LINHARES, W. Creches: como Planificar; mais ou menos? in: Promoção Humana, Revista da Secretaria da Promoção Social, ano II, n. ${ }^{\circ} 10,27-33$.

4 -- LINHARES, W. Creches: como planificar; mais ou menos? in: Centro Infantil da Fundação de Assistência à Infância de Santo André (FAISA) - estudo e projeto de construção.

5 - ODS n. ${ }^{\circ}$ SP-699.55, de 27-9-71, publicado no BS/DS 188, de 1.9-10-71, sobre "normas e critérios gerais para instituição e manutenção do Creches no INPS para filhos de seus servidores".

6 - ROCHA, D. N. Elementos Básicos de Assistência de Enfermagem Pediátrica, in: Servir, coleção de Informações Tecno-profissionais, Darrow Laboratórios S.A., novembro de 1970.

7 - DA POIAN, C. T. Aspectos Psicológicos da Hospitalização da Criança, in: Servir, coleção de Informações Tecno-Profissionais, Darrow Laboratórios S.A., novembro de 1970.

\section{AGRADECIMENTOS}

Este trabalho contou com a orientação inestimável do Arquiteto Adolpho Rubio Morales, de Dr. Waltencir Linhares, pediatra da Creche da Secretaria da Fazenda do Estado de São Paulo, e de Dr. Amaury Amaral Vieira, Coordenador de Planejamento da Superintendência Regional do INPS em São Paulo, cujo apoio e interesse facilitaram os trabalhos de pesquisa em campo. 